\title{
Adsorption and Activity of Lipase on Polyphosphazene-Modified Polypropylene Membrane Surface
}

\author{
Peng-Cheng Chen ${ }^{2}$, Yue-Cheng Qian ${ }^{1,3}$, Fei Fang ${ }^{1}$, Xue-Yan Zhu ${ }^{1}$ and Xiao-Jun Huang ${ }^{1, *}$ \\ 1 MOE Key Laboratory of Macromolecular Synthesis and Functionalization, Department of Polymer Science \\ and Engineering, Zhejiang University, Hangzhou 310027, China; clkxqyc@aliyun.com (Y.-C.Q.); \\ 3090102659@zju.edu.cn (F.F.); 21429008@zju.edu.cn (X.-Y.Z.) \\ 2 The Key Laboratory of Industrial Biotechnology, Ministry of Education, School of Biotechnology, \\ Jiangnan University, Wuxi 214122, China; chenpengcheng@jiangnan.edu.cn \\ 3 Techonology Department, Zhejiang Jinghuan Environmental Technology Co., Ltd., Jinhua 321000, China \\ * Correspondence: hxjzxh@zju.edu.cn; Tel.: +86-571-8827-6294
}

Academic Editor: David D. Boehr

Received: 22 September 2016; Accepted: 27 October 2016; Published: 8 November 2016

\begin{abstract}
In this work, poly(n-butylamino)(allylamino)phosphazene (PBAP) was synthesized and tethered on polypropylene microporous membrane (PPMM) with the aim of offering a biocompatible and, at the same time, moderately hydrophobic microenvironment to lipase for the first time. Lipase from Candida rugosa was used and the influence of membrane surface conditions on the activities of immobilized lipases was evaluated. Water contact angle measurement as well as field emission scanning electron microscopy were used to characterize the morphology of the modified membranes. The results showed an improvement in the adsorption capacity $\left(26.0 \mathrm{mg} / \mathrm{m}^{2}\right)$ and activity retention $(68.2 \%)$ of the immobilized lipases on the PBAP-modified PPMM. Moreover, the lipases immobilized on the modified PPMM showed better thermal and $\mathrm{pH}$ stability.
\end{abstract}

Keywords: lipase; adsorption; membrane modification; polyphosphazene; activity

\section{Introduction}

Lipases are enzymes with the capability to catalyze a wide range of reactions such as hydrolysis, trans-esterification, aminolysis and enantiomer resolution, and they are very promising in the food, pharmaceutical, and detergent industries [1-3]. In practical applications, lipases often go through an immobilization process for better catalytic stability and easier catalyst recycling [4-9]. One remarkable characteristic of lipases is their activation facing a hydrophobic interface, which can induce conformational rearrangements and generate the "open state" of lipases and improve lipases' activity [10]. This characteristic is called interfacial activation [11]. Therefore, special emphasis has been put on immobilizing lipases onto hydrophobic support surfaces in recent years, which is based on the assumption that the active state of lipases can be stabilized by the hydrophobic interaction between the hydrophobic active center of lipases and the hydrophobic support [12-15]. In a previous study, we systematically studied the structural rearrangements, immobilization kinetics and protein aggregation of lipase from Candida rugosa absorbed on a wettability-tailored surface, and concluded that a support with proper hydrophobicity is of vital importance for obtaining a highly efficient immobilized lipase [16].

For a long time, polymeric membranes have been applied in enzyme immobilization due to their structure controllability and the benefit of combining separation with chemical reaction. Among a wide range of membrane materials reported, the polypropylene membrane stands out for its controllable porosity, chemical inertness and high potential for industrial applications $[17,18]$. However, 
its poor biocompatibility may result in protein denaturation and activity loss when used in the lipase immobilization domain. From this point view, it is important to introduce a properly hydrophobic yet, at the same time, bio-friendly interface on the membrane surface for lipase immobilization, which may reduce adverse protein-support interactions and benefit the lipase activity [19-22].

Polyphosphazenes are biocompatible polymers with alternating nitrogen and phosphorous atoms in the backbone $[23,24]$. One promising property of this kind of polymer is its ease of structural manipulation using classical nucleophilic substitution, which enables the incorporation of various side groups. This kind of synthetic flexibility endows polyphosphazenes with tunable physical and chemical properties. The tunable physicochemical and biocompatible properties of polyphosphazenes make them promising in different biotechnological applications, such as drug delivery, biosensors, scaffolding materials and controlled release [25-27]. Moreover, polyphosphazene-based materials have been reported to be efficient supports in enzyme immobilization practices. Cuetos et al. employed $\left\{\mathrm{NP}\left[\mathrm{O}_{2} \mathrm{C}_{12} \mathrm{H}_{8-x}\left(\mathrm{NH}_{2}\right)_{x}\right]\right\} \mathrm{n}$ as a starting material to co-immobilize Baeyer-Villigermono oxygenase and the NADPH recycling enzyme covalently and fabricated a self-sufficient redox biocatalyst [28]. An anionic poly[bis(methacrylate)phosphazene] hydrogel with a reversible enzyme binding capability was prepared by Qian et al. [29].

In this work, poly(n-butylamino)(allylamino)phosphazene (PBAP) was synthesized. The introduction of allylamine and n-butylamine is expected to endow the polymer with hydrophobicity, and the double-bond offered a cross-linking possibility in the further work to better stabilize the immobilized enzymes. PBAP was tethered on polypropylene microporous membrane (PPMM) through coating to form an interface layer for the immobilization of lipase from Candida rugosa by adsorption. The facile modification method is supposed to tailor the surface properties while at the same time do no harm to the bulk conditions. This work is aimed at offering a convenient pathway for PPMM modification and providing a hydrophobic yet biocompatible surface for lipase immobilization.

\section{Results and Discussion}

\subsection{Preparation and Characterization of PBAP with Varied Side Group Ratios}

PBAP was prepared by nucleophilic substitution of $n$-butylamine and allylamine, with FT-IR and ${ }^{1} \mathrm{H}$ NMR spectra to confirm the structure. In the FT-IR spectrum of PBAP presented in Figure 1a, the bands assigned to $\mathrm{C}=\mathrm{C}\left(1640 \mathrm{~cm}^{-1}\right), \mathrm{C}-\mathrm{H}\left(2860 \sim 2930 \mathrm{~cm}^{-1}\right)$ and $\mathrm{P}-\mathrm{N}(\mathrm{H})\left(550 \mathrm{~cm}^{-1}\right)$ demonstrate that alkene and alkyl side groups are successfully incorporated into the polyphosphazene. Moreover, the band at $1224 \mathrm{~cm}^{-1}$ came from P-N. The ${ }^{1} \mathrm{H}$ NMR verified that the chlorine atoms were replaced by these two amine reagents (Figure $1 \mathrm{~b}$ ). The signals at $\delta=4.93-5.17$ and 5.89 are assigned to $\mathrm{CH}_{2}=\mathrm{CH}-$ and $\mathrm{CH}_{2}=\mathrm{CH}-$, respectively. The signal at $\delta=0.89$ corresponds to $\mathrm{CH}_{3}-$. Moreover, the ratio of $n$-butylamino to allylamino in the polymer was tailored by varying the feed ratio, and the ${ }^{1} \mathrm{H}$ NMR spectra of the obtained polymer were also shown in Figure 1b. According to this figure, when feed molar ratios were 1.8:0.2, 1.67:0.33, 1:1, and 0.33:1.67, the calculated side group molar ratios were 1.62:0.38, 1.31:0.69, 0.95:1.05, and 0.33:1.67, respectively. The substitution of chlorine atoms by $n$-butylamino groups was easier than the allylamino group substitution because of the stronger nucleophilic reactivity of $n$-butylamino groups. 
(a)

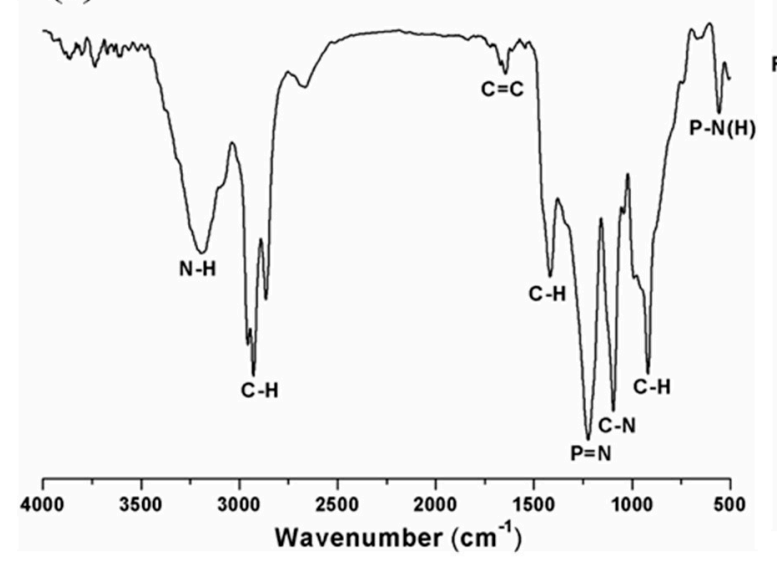

(b)

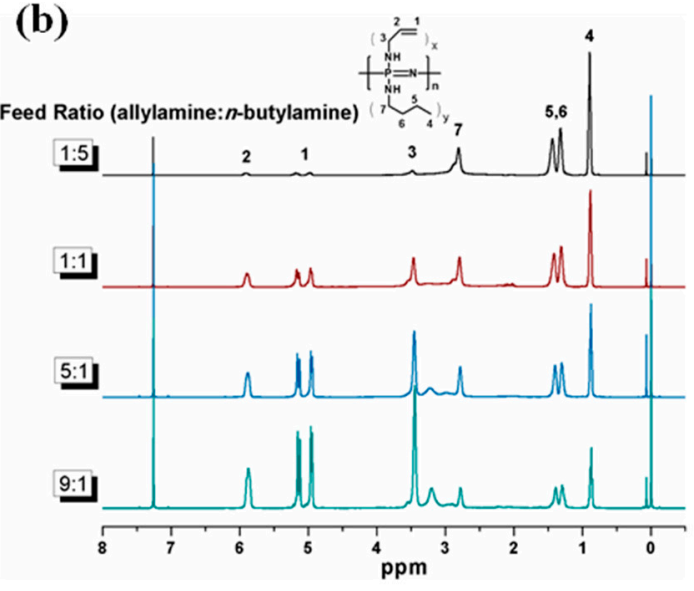

Figure 1. (a) FT-IR; and (b) 1H NMR spectra of PBAP (poly(n-butylamino)(allylamino)phosphazene).

\subsection{Effect of Side Group Ratios on Polymer Hydrophilicity}

Polymeric films were prepared by a spin-coating method on glass and the corresponding water contact angles were tested. The results were shown in Figure 2. According to this figure, the surfaces become more hydrophobic with the increase of $n$-butylamino groups in the polymer. Poly $(n \text {-butylamino })_{1.67}$ (allylamino $)_{0.33}$ phosphazene film had a water contact angle of $113.6^{\circ}$, meaning a $30^{\circ}$ increase compared with that of poly(allylamino)phosphazene. In the previous work done by us, lipase was found to adsorb on the support easily with a water contact angle of $105.9^{\circ}$, with a higher enzyme binding constant value, and the hydrophobic interaction can expose the catalytic site and produce even and regular protein deposition, which activate the lipase [16]. Thus we used poly(n-butylamino $)_{1.05}$ (allylamino $)_{0.95}$ phosphazene with a similar wettability of $108.2^{\circ}$ for further study.

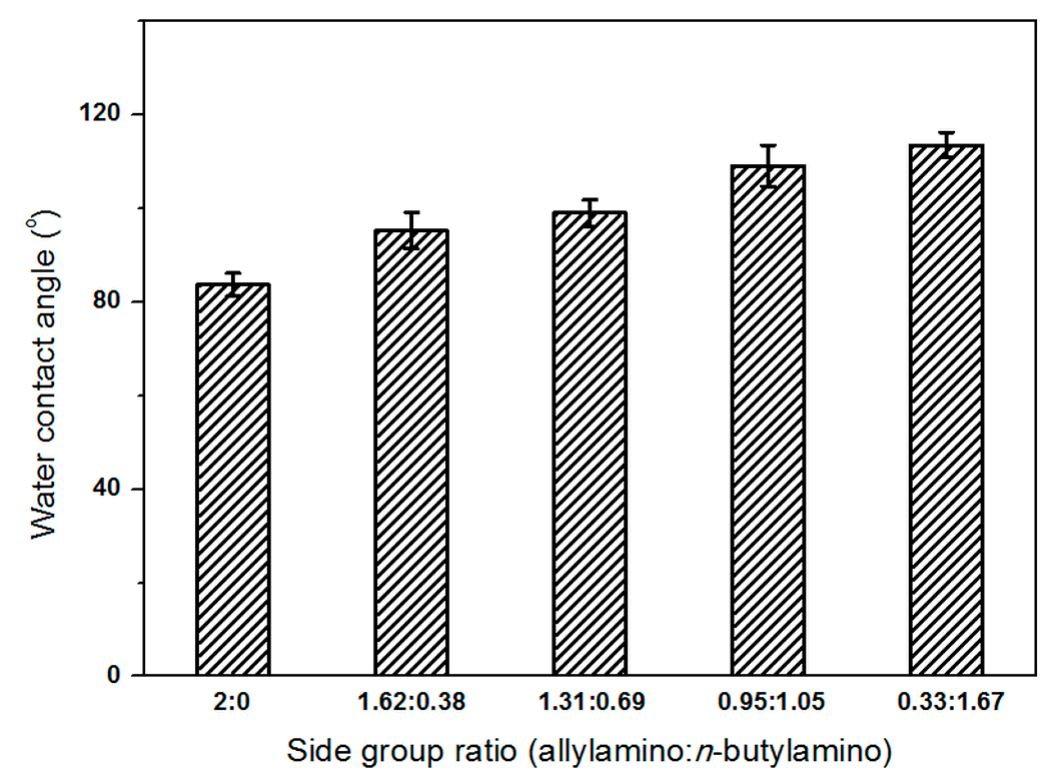

Figure 2. Effect of side group molar ratios on polymer hydrophilicity.

\subsection{Characterization of the PBAP-Modified PPMM}

PPMMs were immersed in PBAP solution with concentrations varying from $2.0 \mathrm{wt} \%$ to $12.0 \mathrm{wt} \%$ for coating. The modification efficiency was evaluated by water contact angle measurement, weighing, 
and field emission scanning electron microscopy (SEM), as was shown in Figures 3 and 4. Obviously, the polymer concentration had little effect on the water contact angles after the modification process, which was due to the similar hydrophilicity of PBAP with that of pristine PPMM. This result is good in view of interfacial activation for lipase immobilization. The membrane weight increased with the increase of the polymer concentration, suggesting a growing amount of polymer tethered on the membrane. From Figure 4 we know generally that PBAP coating will not affect the membrane morphology; however, too high a polymer concentration will block the micropores of PPMM. Moreover, we studies the stability of the PBAP-modified PPMMs by washing them with phosphate buffer solution (PBS, $0.05 \mathrm{M}, \mathrm{pH} 7.0$ ) and THF (solvent to dissolve PBAP) for a week and then measured their weights. PBAP coatings showed good stability in PBS $(0.05 \mathrm{M}, \mathrm{pH} 7.0)$ without weight change upon washing. Tetrahydrofuran did affect their weights, but when the PBAP concentration was less than $8.0 \mathrm{wt} \%$, the modified membrane weight decrease was less than $5 \%$. Based on the facts above, we chose the PPMM which was modified by a $6.0 \mathrm{wt} \%$ PBAP solution for further lipase immobilization; on the one hand, at this concentration, the modified membrane showed good morphology, but on the other hand, the modified membrane was stable.

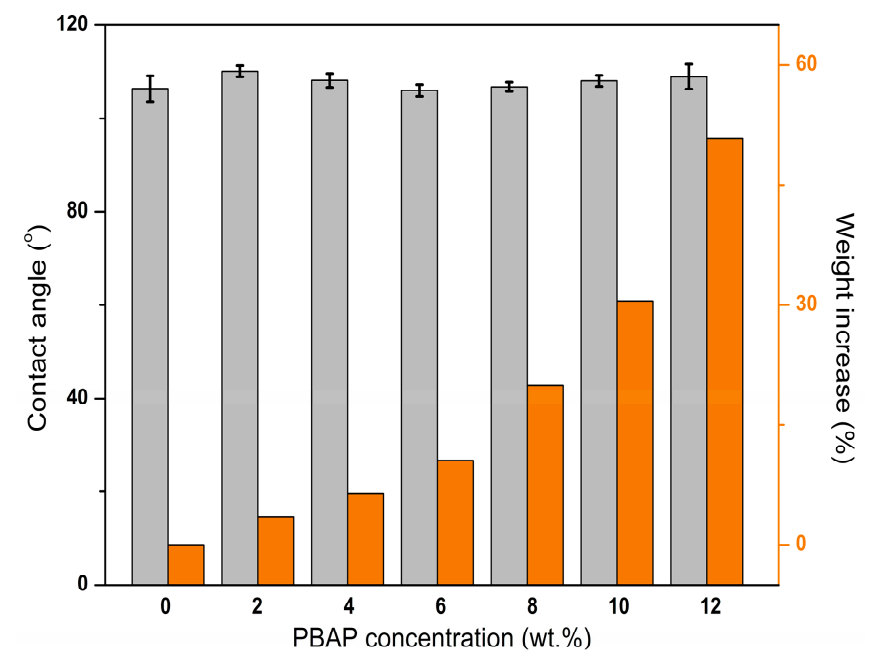

Figure 3. Effect of PBAP concentration on membrane hydrophilicity and weight.
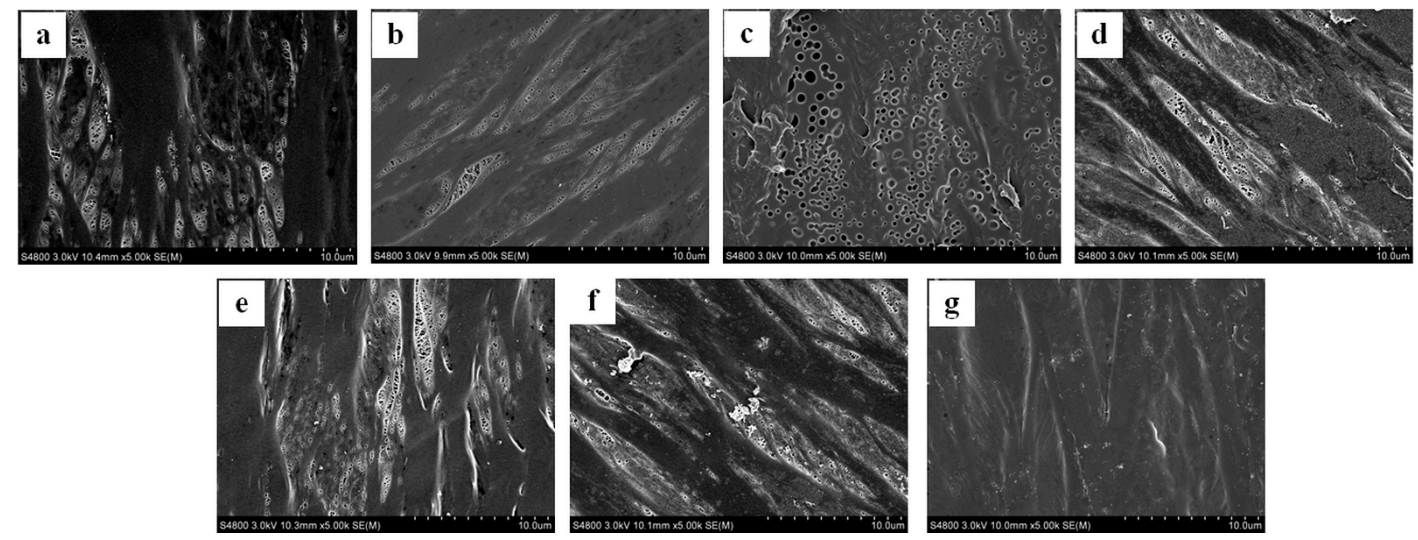

Figure 4. SEM images of PPMM (polypropylene microporous membrane) after PBAP modification.

(a) Pristine PPMM; (b-g) PPMM modified with 2.0, 4.0, 6.0, 8.0, 10.0 and $12.0 \mathrm{wt} \%$ PBAP.

\subsection{Lipase Immobilization and Activity Retention}

Lipase loading curves were shown in Figure 5, with a lipase concentration of $0.2 \mathrm{mg} / \mathrm{mL}$. Enzyme loading on the PBAP-modified PPMM reached $35.6 \mathrm{mg} / \mathrm{m}^{2}$ after absorption balance, 
which was more than that of $26.0 \mathrm{mg} / \mathrm{m}^{2}$ for the pristine PPMM. This result showed that lipases attached more easily to the PBAP-modified PPMM than to the pristine one. For the desorption experiments, we measured the protein concentration in PBS $(0.05 \mathrm{M}, \mathrm{pH} 7.0)$ after the lipase-tethered membranes were incubated at $25^{\circ} \mathrm{C}$. In this case, lipases weakly adsorbed on the membrane surface and inside the membrane pores can be desorbed. According to the figure, the time needed to reach a $10 \%$ lipase desorption ratio was about $8 \mathrm{~h}$ for the pristine PPMM, while the period was prolonged to about $10 \mathrm{~h}$ for the modified one. Both experiments verified an increased adsorption capacity after modification.

Activity measurement is an important criterion for evaluating the immobilization efficiency. The specific activity of free lipase was $41.5 \pm 2.8 \mathrm{U} / \mathrm{mg}$, and the specific activity of lipase adsorbed on PBAP-modified PPMM was $28.3 \pm 2.0 \mathrm{U} / \mathrm{mg}$. Compared with the lipases adsorbed on pristine PPMM, the ones adsorbed on PBAP-modified PPMM had an activity retention that increased from $47.5 \%$ to $68.2 \%$. This encouraging improvement verified that, apart from the hydrophobic characteristic of the PBAP coating that can induce interfacial activation of lipase, its biocompatible property also helped to maintain the lipase activity. The advantages of using biocompatible and biomimetic supports for enzyme immobilization have also been reported by others [30-32]. The biocompatible property also helped to maintain the lipase activity. Moreover, PBAP contained allylamino groups which were able to undergo a wide range of reactions; thus the PBAP-modified PPMM had more functionality possibilities compared with the pristine one.

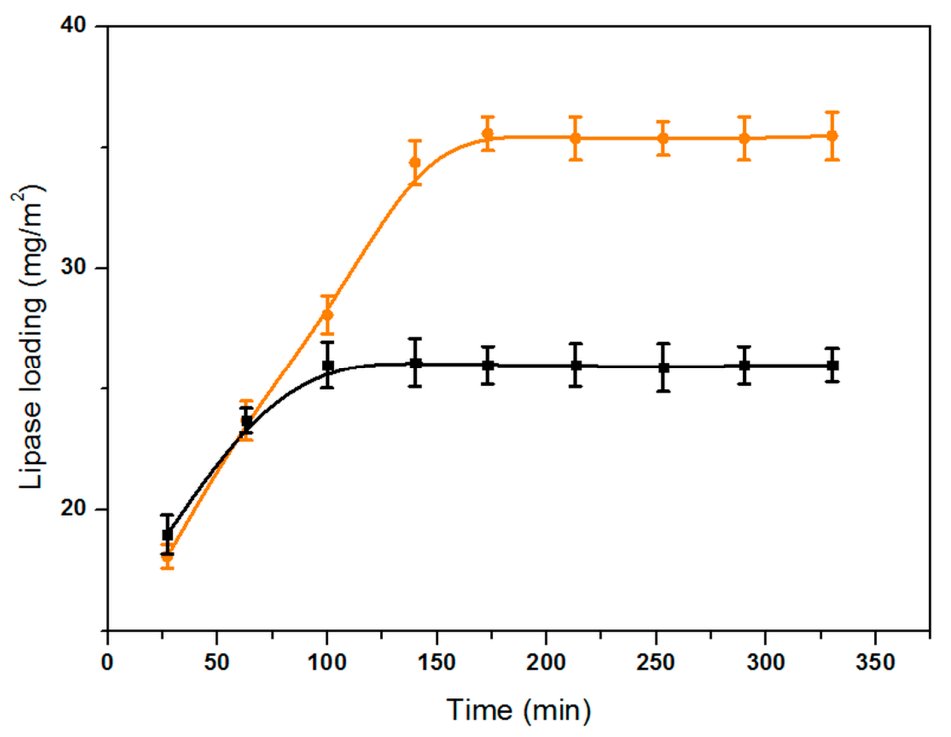

Figure 5. Effect of time on the enzyme loading of lipase on pristine ( $\mathbf{\square}$, black color) and PBAP-modified $(\bullet$, orange color) PPMM.

\subsection{Influence of $\mathrm{pH}$ and Temperature on Lipase Activity}

The influence of $\mathrm{pH}$ on the activity of both the free and the immobilized lipases was shown in Figure 6a. The optimum $\mathrm{pH}$ value for the free lipases was found at about 6.4, whereas that value for the immobilized ones shifted to the alkaline region at about 7.2. It could be explained as, during the immobilization procedure, the active site of lipase became more exposed to solvent than that in the globular, folded and dissolved free lipase form; therefore, proton transfer to the amino acid residues at the active site was promoted. Moreover, according to this figure, the lipase immobilized on PBAP-modified PPMM possessed a wider $\mathrm{pH}$ tolerance range than both the free lipase and the lipase immobilized on pristine PPMM.

According to Figure $6 \mathrm{~b}$, the immobilized lipases on the PBAP-modified PPMM shared the same optimum temperature at $35^{\circ} \mathrm{C}$ with the free lipases. The immobilized lipase showed an improved 
resistance to thermal denaturation. After adsorption on the pristine PPMM, the optimum temperature shifted to $45^{\circ} \mathrm{C}$. This phenomenon could be ascribed to a lower mass transfer resistance of the substrate and product at a higher reaction temperature; also, a higher substrate solubility in the PPMM film creating local environment differences could be ascribed to. Comparing these two immobilized lipases, although the optimal temperature for the lipase immobilized on PBAP-modified PPMM was lower than the one immobilized on pristine PPMM, the former has a better thermal stability than the latter at above $45^{\circ} \mathrm{C}$.
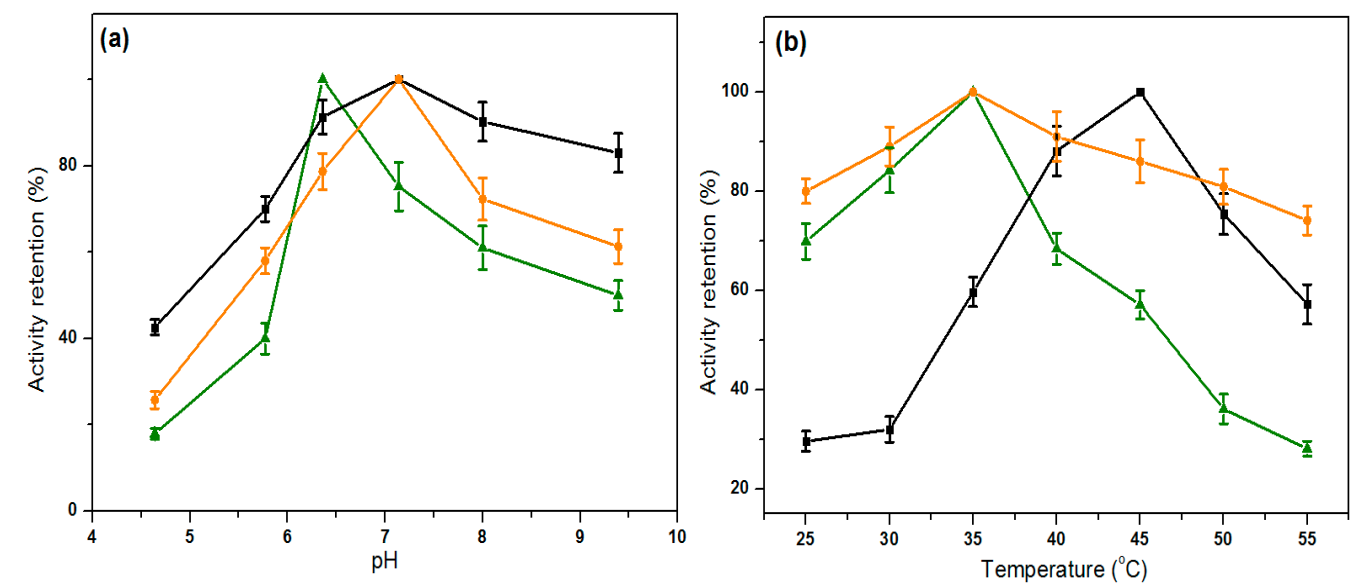

Figure 6. Influence of $\mathrm{pH}(\mathbf{a})$; and temperature (b) on activity retention. Free lipase ( $\boldsymbol{\Lambda}$, green color), lipase immobilized on pristine PPMM (ם, black color), lipase immobilized on PBAP-modified PPMM

$(\bullet$, orange color).

\subsection{Thermal Stability of the Immobilized Lipases}

Figure 7 showed the activity retention of both the free and immobilized lipases at $55{ }^{\circ} \mathrm{C}$. It can be seen that free lipase was totally deactivated within $70 \mathrm{~min}$. Lipase immobilized on the PBAP-modified PPMM preserved $58 \%$ of the initial activity at $100 \mathrm{~min}$, which was 7.5 times the value obtained on the pristine PPMM. The interaction between the enzyme and support induced a higher thermal stability of the immobilized lipases, which can prevent the conformational denaturation of the enzymes at a higher temperature. Moreover, regarding the PBAP, the short-side alkyls were hydrophobic and offered more opportunities for interaction with the immobilized lipases, thus helping to stabilize lipase conformation and improve the resistance of lipase to heat.

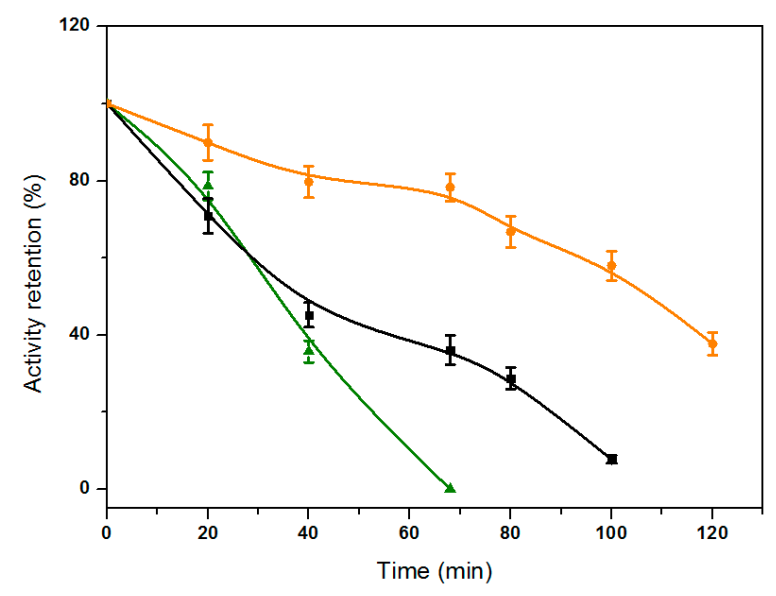

Figure 7. Thermal stabilities of lipases. Free lipase ( $\mathbf{\Lambda}$, green color), lipase immobilized on pristine $\operatorname{PPMM}(\boldsymbol{\square}$, black color), lipase immobilized on PBAP-modified PPMM (•, orange color). 


\section{Materials and Methods}

\subsection{Materials}

Hexachlorocyclotriphosphazene (HCCP) was purchased from Boyuan New Material \& Technology Co. Ltd., Ningbo, China, and was purified by recrystallization from heptane at $60{ }^{\circ} \mathrm{C}$, followed by vacuum sublimation twice. Poly(dichlorophosphazene) (PDCP) was prepared by thermally initiated ring-opening polymerization of $\mathrm{HCCP}$ under $\mathrm{N}_{2}$ atmosphere at $250{ }^{\circ} \mathrm{C}$ [24]. Tetrahydrofuran (THF) was dried by refluxing over a $\mathrm{Na} / \mathrm{K}$ alloy and distilled under $\mathrm{N}_{2}$ atmosphere. Allylamine, $\mathrm{n}$-butylamine as well as triethylamine were obtained from Sinopharm Chemical Reagent Co. Ltd. (Shanghai, China) and used directly. Lipase from Candida rugosa (1150 units/mg solid), bovine serum albumin (BSA, molecular mass: 67,000 Da) and Bradford reagent were purchased from Sigma-Aldrich Chemical Co. (St. Louis, MO, USA) and used without further purification. All other chemicals were of analytical grade and used as received.

\subsection{Preparation and Analysis of PBAP}

PDCP $(1.00 \mathrm{~g}, 17.2 \mathrm{mmol} \mathrm{Cl})$ was washed with petroleum ether to remove any monomers and oligomers remained, and then dissolved in $100 \mathrm{~mL}$ of dry THF under $\mathrm{N}_{2}$ protection. Triethylamine $(2.02 \mathrm{~g}, 20.0 \mathrm{mmol})$, allylamine and n-butylamine (the total amount of allylamine and $n$-butylamine was $20.0 \mathrm{mmol}$ ) were then put simultaneously to the solution. The mixture was stirred for $24 \mathrm{~h}$ at room temperature. Afterwards, the mixture was filtrated to remove the solids and the solution left was precipitated in water. The obtained polymer was dried overnight in vacuum at room temperature.

FT-IR and ${ }^{1} \mathrm{H}$ NMR were applied to characterize the chemical structure of PBAP. The FT-IR spectrum of PBAP in KBr was recorded on a Brucker Vector 22 FT-IR spectrometer Bruker Biospin Corporation, Billerica, MA, USA), while the ${ }^{1} \mathrm{H}$ NMR spectra of the polymer solution in $\mathrm{CDCl}_{3} \mathrm{were}$ obtained on a Brucker Advance DMX500 nuclear magnetic resonance spectrometer (Bruker Biospin Corporation, Billerica, MA, USA).

\subsection{Surface Modification of PPMM with PBAP}

The pristine PPMM was washed in acetone for $24 \mathrm{~h}$, then in plenty of de-ionized water and dried at room temperature in vacuum before use. PBAP was dissolved in THF with concentrations varied from $2.0 \mathrm{wt} \%$ to $12.0 \mathrm{wt} \%$. The pretreated PPMM was submerged in PBAP solution and shaken in a water bath at $25^{\circ} \mathrm{C}$ for $6 \mathrm{~h}$. The ratio of membrane area to PBAP solution volume was $10: 1 \mathrm{~cm}^{2}: \mathrm{cm}^{3}$, which ensured a sufficient contact between membrane and PBAP solution. Afterwards, the membranes were taken out and washed with an excess amount of de-ionized water before dried at room temperature in vacuum.

The hydrophilicity of PPMM before and after modification process was characterized regarding to water contact angle on a CTS-200 system (Mighty Technology Pvt. Ltd., Ningbo, China). Typical experiment was operated by a sessile drop method as follows at room temperature. A water drop $(2.0 \mu \mathrm{L})$ was lowered onto the membrane surface from a needle tip; then, the droplet images were recorded and water contact angles were calculated from these images with software. Each reported value was an average of at least five independent measurements.

Field emission scanning electron microscopy (SEM, SIRION-100, FEI, Hillsboro, OR, USA) was applied to observe the membrane surface morphology after sputtered with gold using ion sputter JFC-1100 (JFC Japan Inc., Tokyo, Japan).

\subsection{Immobilization of Lipase by Adsorption}

Lipase solutions were prepared by dissolving appropriate amounts of lipase powder to phosphate buffer solution (PBS, 0.05 M, pH 7.0). Supports (the pristine and PBAP-modified PPMMs) were submerged in lipase solution and shaken at $25^{\circ} \mathrm{C}$ for $6 \mathrm{~h}$. The ratio of membrane area to lipase solution volume was 10:1 $\left(\mathrm{cm}^{2}: \mathrm{cm}^{3}\right)$. Afterwards, the membranes were taken out and washed thoroughly with 
PBS (0.05 M, pH 7.0) until no protein was found in washings. Lipase concentration in solutions was determined with Coomassie Brilliant Blue reagent using Bradford's method [33,34]. The amount of lipase adsorbed on membrane was calculated by the difference of initial and final lipase concentrations in the enzyme solutions and the washings, with BSA as the standard to construct the calibration curve. Enzyme loading was defined as the amount of enzyme $(\mathrm{mg})$ per square meter of the membrane. Each value was the average of three parallel experiments at least, and the standard deviation should be within ca. $\pm 5 \%$.

\subsection{Assay of Lipase Activity}

The lipase activity was determined using a method previously reported [35]. Briefly, the reaction was started by putting immobilized lipase preparation in the reaction mixture composed of $1.0 \mathrm{~mL}$ ethanol containing $14.4 \mathrm{mM} p$-nitrophenyl palmitate and $1.0 \mathrm{~mL}$ PBS $(0.05 \mathrm{M}, \mathrm{pH} 7.0)$. The mixture was then gently shaken at $25^{\circ} \mathrm{C}$. After $5 \mathrm{~min}, 2.0 \mathrm{~mL} 0.5 \mathrm{M} \mathrm{Na}_{2} \mathrm{CO}_{3}$ was used to terminate the reaction, followed by centrifuging for $10 \mathrm{~min}$ at $10,000 \mathrm{rpm}$. The supernatant $(0.50 \mathrm{~mL})$ was diluted 10 folds with de-ionized water, and then measured in an UV-vis spectrophotometer (UV-2450, Shimadzu, Japan) at $410 \mathrm{~nm}$ against a blank without enzyme and treated in parallel.

One enzyme unit is defined as the amount of biocatalyst generating $1.0 \mu \mathrm{mol}$ p-nitrophenol $\mathrm{min}^{-1}$ in this condition. Activity retention value was the ratio of immobilized lipase activity to that of free one. Each data was the mean of at least three parallel experiments, and the standard deviation was within ca. $\pm 5 \%$.

\subsection{Stability Measurements}

Activity of free and immobilized lipases under different $\mathrm{pH}$ values was determined by incubated in different reaction mixtures at $\mathrm{pH}$ of 4.6, 5.7, 6.4, 7.2, 7.5, 8.0 and 9.4. The relative activities of both free and immobilized lipase were normalized to their highest activity under the assay $\mathrm{pH}$ range. Activities of free and immobilized lipases at different temperatures elevated from $25^{\circ} \mathrm{C}$ to $55^{\circ} \mathrm{C}$ were determined. And the relative activities were also normalized to the highest activity within this temperature range. For the measurement of thermal stability, both free and immobilized lipases were kept at $55{ }^{\circ} \mathrm{C}$ for $120 \mathrm{~min}$. Samples were periodically taken out with their residual activities measured.

\section{Conclusions}

In order to realize interfacial activation and, at the same time, offer a biocompatible microenvironment for immobilized lipase, PBAP was synthesized by nucleophilic substitution method and coated on PPMM. The ratio of $n$-butylamino and allylamino groups in PBAP was optimized and poly(n-butylamino $)_{1.05}$ (allylamino $)_{0.95}$ phosphazene with a wettability of $108.2^{\circ}$ was chosen for the coating process at a solution concentration of $6.0 \mathrm{wt} \%$. Results showed that compared with the lipases adsorbed on pristine PPMM, the ones adsorbed on PBAP-modified PPMM had an activity retention that increased from $47.5 \% \pm 2.0 \%$ to $68.2 \% \pm 3.9 \%$. Moreover, the short hydrophobic side alkyls in PBAP offered more opportunities for interaction with the immobilized lipases, thus helping to stabilize protein conformation.

Acknowledgments: The authors are grateful for the financial support from the National Natural Science Foundation of China (Grant No. 21274126 and Grant No. 21604032), the Open Project of Key Laboratory of Industrial Biotechnology, Ministry of Education, Jiangnan University (Grant No. KLIB-KF201501), the Fundamental Research Funds for the Central Universities (Grant No. JUSRP51504 and JUSRP116031), the Industry-University-Institute Cooperative Program in Jiangsu Province (Grant No. BY2015019-37) and the Key Projects in the National Science \& Technology Pillar Program during the Twelfth Five-Year Plan Period (Grant No. 2015BAD15B04).

Author Contributions: Peng-Cheng Chen and Yue-Cheng Qian designed the research and wrote the paper; Peng-Cheng Chen and Yue-Cheng Qian performed the experiments; Fei Fang and Xue-Yan Zhu contributed analysis tools; Xiao-Jun Huang supervised research. All authors read and approved the final manuscript.

Conflicts of Interest: The authors declare no conflict of interest. 


\section{References}

1. Ragupathy, L.; Pluhar, B.; Ziener, U.; Keller, H.; Dyllick-Brenzinger, R.; Landfester, K. Enzymatic aminolysis of lactones in aqueous miniemulsion: Catalysis through a novel pathway. J. Mol. Catal. B Enzym. 2010, 62, 270-276. [CrossRef]

2. Pan, C.; Luan, Z.Q.; Wang, X.J.; Ma, L. In situ immobilization of horseradish peroxidase on electropsun poly(styrene-co-methacrylic acid) nanofiberous membrane for catalytic treatment of polyphenol. Acta Polym. Sin. 2013, 12, 1508-1513.

3. Ye, R.; Hayes, D.G.; Burton, R.; Liu, A.J.; Harte, F.M.; Wang, Y.M. Solvent-free lipase-catalyzed synthesis of technical-grade sugar esters and evaluation of their physicochemical and bioactive properties. Catalysts 2016, 6. [CrossRef]

4. Chen, P.C.; Huang, X.J.; Xu, Z.K. Kinetics-bolstered catalytic study of a high performance lipase-immobilized nanofiber membrane reactor. RSC Adv. 2014, 4, 6151-6158. [CrossRef]

5. Vaghari, H.; Jafarizadeh-Malmiri, H.; Mohammadlou, M.; Berenjian, A.; Anarjan, N.; Jafari, N.; Nasiri, S. Application of magnetic nanoparticles in smart enzyme immobilization. Biotechnol. Lett. 2016, 38, $223-233$. [CrossRef]

6. Barbosa, O.; Ortiz, C.; Berenguer-Murcia, Á.; Torres, R.; Rodrigues, R.C.; Fernandez-Lafuente, R. Strategies for the one-step immobilization-purification of enzymes as industrial biocatalysts. Biotechnol. Adv. 2015, 33, 435-456. [CrossRef]

7. Min, K.; Yoo, Y.J. Recent progress in nanobiocatalysis for enzyme immobilization and its application. Biotechnol. Bioprocess Eng. 2014, 19, 553-567. [CrossRef]

8. Barbosa, O.; Torres, R.; Ortiz, C.; Berenguer-Murcia, A.; Rodrigues, R.C.; Fernandez-Lafuente, R. Heterofunctional supports in enzyme immobilization: From traditional immobilization protocols to opportunities in tuning enzyme properties. Biomacromolecules 2013, 14, 2433-2462. [CrossRef]

9. Rodrigues, R.C.; Ortiz, C.; Berenguer-Murcia, A.; Torres, R.; Fernández-Lafuente, R. Modifying enzyme activity and selectivity by immobilization. Chem. Soc. Rev. 2013, 42, 6290-6307. [CrossRef]

10. Verger, R. Interfacial activation of lipase: Facts and artifacts. Trends Biotechnol. 1997, 15, 32-38. [CrossRef]

11. Brzozowski, A.M.; Derewenda, U.; Derewenda, Z.S.; Dodson, G.G.; Lawson, D.M.; Turkenburg, J.P.; Bjorking, F.; Huge-Jensen, B.; Patrk, S.A.; Thim, L. A model for interfacial activation in lipases from the structure of a fungal lipase-inhibitor complex. Nature 1991, 351, 491-494. [CrossRef]

12. Manoel, E.A.; dos Santos, J.C.S.; Freire, D.M.G.; Rueda, N.; Fernandez-Lafuente, R. Immobilization of lipases on hydrophobic supports involves the open form of the enzyme. Enzyme Microb. Tech. 2015, 71, 53-57. [CrossRef]

13. Mateo, C.; Palomo, J.M.; Fernandez-Lorente, G.; Guisan, J.M.; Fernandez-Lafuente, R. Improvement of enzyme activity, stability and selectivity via immobilization techniques. Enzyme Microb. Tech. 2007, 40, 1451-1463. [CrossRef]

14. Adlercreutz, P. Immobilisation and application of lipase in organic media. Chem. Soc. Rev. 2013, 42, 6406-6436. [CrossRef]

15. Santos, J.C.; Barbosa, O.; Ortiz, C.; Berenguer-Murcia, A.; Rodrigues, R.C.; Fernandez-Lafuente, R. Importance of the support properties for immobilization or purification of enzymes. ChemCatChem 2015, 7, 2413-2432. [CrossRef]

16. Chen, P.C.; Huang, X.J.; Xu, Z.K. Activation and deformation of immobilized lipase on self-assembled monolayers with tailored wettability. Phys. Chem. Chem. Phys. 2015, 17, 13457-13465. [CrossRef]

17. Zhao, K.Y.; Lin, B.B.; Cui, W.K.; Feng, L.Z.; Chen, T.; Wei, J.F. Preparation and adsorption of bovine serum albumin-imprinted polyacrylamide hydrogel membrane grafted on non-woven polypropylene. Talanta 2014, 121, 256-262. [CrossRef]

18. Makhloufi, C.; Asseuguette, E.; Remigy, J.C.; Belaissaoui, B.; Roizard, D.; Favre, E. Ammonia based $\mathrm{CO}_{2}$ capture process using hollow fiber membrane contactors. J. Membr. Sci. 2013, 455, 236-246. [CrossRef]

19. Secundo, F. Conformational changes of enzymes upon immobilisation. Chem. Soc. Rev. 2013, 42, 6250-6261. [CrossRef]

20. Cantone, S.; Ferrario, V.; Corici, L.; Ebert, C.; Fattor, D.; Spizzo, P.; Gardossi, L. Efficient immobilisation of industrial biocatalysts: Criteria and constraints for the selection of organic polymeric carriers and immobilisation methods. Chem. Soc. Rev. 2013, 42, 6262-6276. [CrossRef] 
21. Brady, D.; Jordaan, J. Advances in enzyme immobilisation. Biotechnol. Lett. 2009, 31, 1639-1650. [CrossRef]

22. Sheldon, R.A.; Van Pelt, S. Enzyme immobilisation in biocatalysis: Why, what and how. Chem. Soc. Rev. 2013, 42, 6223-6235. [CrossRef]

23. Allcock, H.R.; Phelps, M.V.B.; Barrett, E.W. Ultraviolet photolithographic development of polyphosphazene hydrogel microstructures for potential use in microarray biosensors. Chem. Mater. 2006, 18, 609-613. [CrossRef]

24. Qian, Y.C.; Huang, X.J.; Chen, C.; Ren, N.; Huang, X.; Xu, Z.K. A versatile approach to the synthesis of polyphosphazene derivatives via the thiol-ene reaction. J. Polym. Sci. Pol. Chem. 2012, 50, 5170-5176. [CrossRef]

25. Potta, T.; Chun, C.J.; Song, S.C. Dual cross-linking systems of functionally photo-cross-linkable and thermoresponsive polyphosphazene hydrogels for biomedical applications. Biomacromolecules 2010, 11, 1741-1753. [CrossRef]

26. Qian, Y.C.; Ren, N.; Huang, X.J.; Chen, C.; Yu, A.G.; Xu, Z.K. Glycosylation of polyphosphazene nanofibrous membrane by click chemistry for protein recognition. Macromol. Chem. Phys. 2013, 214, 1852-1858. [CrossRef]

27. Xue, L.W.; Mao, L.X.; Cai, Q.; Yang, X.P.; Jin, R.G. Preparation of amino acid ester substituted polyphosphazene microparticles via electrohydrodynamic atomization. Polym. Adv. Technol. 2011, 22, 2009-2016. [CrossRef]

28. Cuetos, A.; Valenzuela, M.L.; Gotor, V.; Carriedo, G.A. Polyphosphazenes as tunable and recyclable supports to immobilize alcohol dehydrogenases and lipases: Synthesis, catalytic activity, and recycling efficiency. Biomacromolecules 2010, 11, 1291-1297. [CrossRef]

29. Qian, Y.C.; Chen, P.C.; Huang, X.J. Click synthesis of ionic strength-responsive polyphosphazene hydrogel for reversible binding of enzymes. RSC Adv. 2015, 5, 44031-44040. [CrossRef]

30. Li, X.D.; Wu, J.; Jia, D.C.; Wan, Y.H.; Yang, N.; Qiao, M. Preparation of cross-linked glucoamylase aggregates immobilization by using dextrin and xanthan gum as protecting agents. Catalysts 2016, 6. [CrossRef]

31. Apetrei, C.; de Saja, J.A.; Zurro, J.; Rodríguez-Méndez, M.L. Advantages of the biomimetic nanostructured films as an immobilization method vs. the carbon paste classical method. Catalysts 2012, 2, 517-531. [CrossRef]

32. Huang, X.J.; Yu, A.G.; Jiang, J.; Pan, C.; Qian, J.W.; Xu, Z.K. Surface modification of nanofibrous poly(acrylonitrile-co-acrylic acid) membrane with biomacromolecules for lipase immobilization. J. Mol. Catal. B Enzym. 2009, 57, 250-256. [CrossRef]

33. Bradford, M. A rapid and sensitive method for the quantition of microgram quantities of protein utilizing the principle of dyebinding. Anal. Biochem. 1976, 72, 248-254. [CrossRef]

34. Zhang, P.; Wang, Q.Q.; Zhang, J.N.; Li, G.H.; Wei, Q.F. Preparation of amidoxime-modified polyacrylonitrile nanofibers immobilized with laccase for dye degradation. Fibers Polym. 2014, 15, 30-34. [CrossRef]

35. Huang, X.J.; Chen, P.C.; Huang, F.; Ou, Y.; Chen, M.R.; Xu, Z.K. Immobilization of Candida rugosa lipase on electrospun cellulose nanofiber membrane. J. Mol. Catal. B Enzym. 2011, 70, 95-100. [CrossRef] 